\title{
Development and characterization of microemulsions containing Tiliacora triandra Diels as an active ingredient for antioxidant and melanogenesis stimulating activities
}

\author{
Sitthiphong Soradech ${ }^{1 *}$, Pokchut Kusolkumbot ${ }^{2}$, Sirinan Thubthimthed ${ }^{1}$ \\ ${ }_{2}^{1}$ Expert Centre of Innovative Herbal Products, Thailand Institute of Scientific and Technological Research, Pathum Thani, Thailand. \\ ${ }^{2}$ Biodiversity Research Centre, Thailand Institute of Scientific and Technological Research, Pathum Thani, Thailand.
}

\section{ARTICLE INFO \\ Article history: \\ Received on: 27/11/2017 \\ Accepted on: 22/02/2018 \\ Available online: 30/03/2018}

\section{Key words:}

Microemulsions, Tiliacora

triandra Diels, Antioxidant

activity, Melanogenesis

stimulating activity,

Stability.

\begin{abstract}
The aimed of this study was to develop microemulsions comprising ethanolic leaf extract of the Tiliacora triandra Diels. (YL) as the potential active ingredient for antioxidant and melanogenesis stimulating activities. The YL extracts were prepared using macerating (MT) and batch stirring extraction (BSE) methods. The antioxidant and melanogenesis stimulating activities of each extracts with different extract conditions were investigated. The suitable condition was further developed to microemulsions (MEs). The pseudoternary phase diagram was developed for the MEs consisting oil mixture as an oil phase, tween 80 as a surfactant, $95 \%$ ethanol as a co-surfactant, and deionized water. The physicochemical properties, stability and cytotoxicity of the YL extract loaded ME were also evaluated. The results showed that YL extract from BSE method at $30^{\circ} \mathrm{C}$ exhibited high potential for DPPH radical scavenging and stimulating tyrosinase. No cytotoxic to human dermal skin fibroblast and melanoma $\left(\mathrm{B}_{16} \mathrm{~F}_{10}\right)$ cells at $0.001-1.0$ $\mathrm{mg} / \mathrm{mL}$ and its potential on stimulating melanin content at $0.05-1.0 \mathrm{mg} / \mathrm{mL}$ of YL extract were both achieved. Next, a study was designed to develop YL extract loaded microemulsions (ME). The optimized YL extract loaded ME had a droplet size in the range of 10.29 to $13.54 \mathrm{~nm}$ with narrow particle size distribution. All formulations of MEs showed good stability after accelerated condition. The release rate of the phenolic content of the YL extract from the ME was slower than that of the aqueous formulation. The YL extract loaded ME showed no cytotoxic to human dermal skin fibroblast and melanoma $\left(\mathrm{B}_{16} \mathrm{~F}_{10}\right)$ cells at 0.001 to $1.0 \mathrm{mg} / \mathrm{mL}$. In conclusion, the obtained YL extract microemulsions exhibited good characteristics in terms of being a potential active ingredient in antioxidant and melanogenesis stimulating activities for anti-grey hair treatment.
\end{abstract}

\section{INTRODUCTION}

Melanin is a pigment that contributes to the color of skin and hair. An abnormality of melanin synthesis results in a decrease in melanin content, causing the graying or fading of hair color. The onset of gray or white hair in Thailand generally happens during the late thirties to mid-forties (Somvong and Prasitpuriprecha, 2013) and can occur as a result of three different mechanisms: I) Increasing oxidative stress in hair cells, II) Reduction in melanocyte cells and III) Reduction in tyrosinase enzyme. The

\footnotetext{
${ }^{*}$ Corresponding Author

Sitthiphong Soradech, Expert Centre of Innovative Herbal Products, Thailand Institute of Scientific and Technological Research, Pathum Thani, Thailand.E-mail: Sitthiphong@ tistr.or.th
}

increasing oxidative stress in hair cells causes the production of hydrogen peroxide in those hair cells, resulting in a reduction in the number of melanin cells and hence, a lower production of melanin content occurs. The reduction of melanocyte cells attributes to a lower production of melanin content. The decrease in tyrosinase as an enzyme for melanin production has a direct effect on the production of melanin content (Tobin and Paus, 2001). Although gray or white hair does not cause any medical problems, it can make people appear older than their actual age, which can consequently have detrimental effects to that person's personality and self-esteem (Tobin and Paus, 2001; Teansuwan et al., 2016). Recently, many research studies have looked at Thai traditional medicinal (from plants) and its application to treat/prevent the onset of gray hair (Teansuwan et al., 2016; Soradech et al., 2016; 
Soradech et al., 2016). Teansuwan et al. (2016) found that aqueousethanolic extracts of these four plants i.e, Eclipta prostrata L. (EP), Zingiber officinale Roscoe. (ZO), Lawsonia inermis L. (LI) and Rhinacanthus nasutus (L.) Kurz. (RN) increased melanin content in melanocytes and may be used as a hair treatment to decrease gray-hair. Soradech et al. (2016) found that the various varieties of Oryza sativa extracts contained high levels of antioxidants which enable the stimulation of melanogenesis activity, providing an increase in the potential value-added properties of various varieties of Oryza sativa extracts. Soradech et al. (2016) found that Clitoria ternatea, Antidesma puncticulatum and Oryza sativa could stimulate melanocyte proliferation among all tested extracts, and the proliferation index (P.I.) scores of these extracts $(500 \mu \mathrm{g} /$ $\mathrm{mL}$ ) were 1.5, 1.3, and 1.3, respectively.

Yanang, Tiliacora triandra Diels, a member of the Menispermaceae family, is a flowering plant native to mainland Southeast Asia and widespread in Northeast Thailand. Extracts from Yanang leaves contain high amounts of polyphenol constituents possessing antioxidant activity which may be attributed to having a high potential for melanogenesis stimulating activity for gray hair treatment (Somvong and Prasitpuriprecha, 2013; Soradech et al., 2017). Soradech et al. (2017) investigated phytochemical constituent and antioxidant activity of $T$. triandra leaf ethanolic extract which indicated the total phenolic content of Yanang leaf extract was $6,663.89 \mathrm{mg}$ GAE/100g extract with comprised gallic acid and epigallocatechin gallate as the chemical constituents. The ethyl acetate extract of $T$. triandra had the strongest stimulating activity with a $94.34 \%$ rate of stimulation. The stimulating activity of melanocyte proliferation of extracts showed that methanol extract of aqueous extract of $T$. triandra had strong stimulating activities with a proliferation index (P.I.) score of 1.6 (Somvong and Prasitpuriprecha, 2013). Therefore, this extract had the potential for antioxidant and melanogenesis stimulating activities. However, there are limitations regarding the use of T. triandra as an active ingredient for antioxidant and melanogenesis stimulating activities for gray hair treatment, such as its instability at ambient temperature, low solubility, inability to be control-released and a low delivery rate to the hair follicles. Therefore, microemulsions, which possess several advantages such as enhancing the solubility of both lipophilic and hydrophilic compounds, higher stability, and efficacy enhancement over conventional formulations, were investigated for loading the $T$. triandra extract for hair treatment application.

Microemulsions (MEs) is one of the cosmetic delivery systems which can be defined as being optically isotropic and transparent in oil or water dispersions with diameters slightly greater than swollen micelles. The particle sizes of microemulsions are in the range of 10-200 nm. A microemulsion system contains water, oil and amphiphile that all are thermodynamically stable with low viscosity and Newtonian behavior (Acharya et al., 2012). The components of MEs are usually optimized by using pseudoternary phase diagrams which present the suitable amount of oil, water and surfactant mixtures. The ME region can be identified in the phase diagram. Microemulsions can be categorized into three types: oil in water $(\mathrm{O} / \mathrm{W})$, water in oil (W/O) and bicontinuous ME. MEs have been reported to enhance the solubility and oxidation stability of Silymarin and ascorbyl palmitate. Therefore, microemulsion systems present attractive skin and hair formulations that can be used not only to investigate improvements in the stability of $T$. triandra extract but also the rate of delivery of its active compounds through the skin barrier, thus obtaining better biological results (Acharya et al., 2012; Kreilgaard, 2002).

Therefore, this study aimed to develop microemulsions comprising ethanolic leaf extract of yanang ( $T$. triandra) as an active ingredient for antioxidant and melanogenesis stimulating activities. The leaf extract of Tiliacora triandra $(\mathrm{YL})$ was prepared by maceration and batch stirring methods. The antioxidant and melanogenesis stimulating activities of each extract with different conditions for the extractions were investigated. A pseudoternary phase diagram was developed for the ME consisting of an oil mixture (olive oil, rice bran oil, coconut oil, oleic acid and PEG -12 dimethicone) as an oil phase, Tween 80 as a surfactant, ethanol as a co-surfactant, and deionized water. The physicochemical properties, cytotoxicity, stability and In vitro release of the YL extract loaded-ME were also evaluated. The physical stabilities of the ME and YLME were investigated over 6 cycles of alternative heating and cooling.

\section{MATERIALS AND METHODS}

\section{Materials}

Theophylline was purchased from Sigma-Aldrich, St. Louis, MO, USA while Absolute ethanol was obtained from Liquor Distillery Organization, Excise Department, Ministry of Finance, Chachoengsao, Thailand. Acetic acid was purchased from RCI Labscan Ltd., Bangkok, Thailand. Ammonium molybdate was purchased from Fisher Scientific UK Ltd., Loughborough, UK while Anhydrous sodium sulfate was purchased from Ajax Finechem, New South Wales, Australia. Bovine serum albumin purchased from Amresco, Ohio, USA. Other chemicals and reagents (analytical grade or higher) were obtained from local distributors and used as received without further purification.

\section{Cell cultures}

$\mathrm{B}_{16} \mathrm{~F}_{10}$ melanoma cells were cultured in $75 \mathrm{~cm}^{2}$ flask in Dulbecco's modified Eagle medium (DMEM) supplemented with $10 \%$ fetal bovine serum (FBS) and $1 \%$ penicillin/streptomycin at $37^{\circ} \mathrm{C}$ in a humidified incubator with $5 \%$ carbon dioxide $\left(\mathrm{CO}_{2}\right)$. Cells were grown to semiconfluence and harvested by $0.25 \%$, w/v trypsin and $0.06 \mathrm{mM}$ ethylenediamine tetraacetic acid (EDTA) in phosphate buffer saline (PBS). Cells were resuspended in the complete DMEM and the cell numbers were counted by using a hemacytometer. Human skin fibroblasts were obtained from Faculty of Dentistry, Chiang Mai University, Chiang Mai, Thailand) which were cultured in $75 \mathrm{~cm}^{2}$ flask in Dulbecco's modified Eagle medium (DMEM) supplemented with 10\% fetal bovine serum (FBS) and $1 \%$ penicillin/streptomycin at $37^{\circ} \mathrm{C}$ in a humidified incubator with $5 \%$ carbon dioxide $\left(\mathrm{CO}_{2}\right)$. Cells were grown to semiconfluence and harvested by $0.25 \%$, w/v trypsin and $0.06 \mathrm{mM}$ ethylenediamine tetraacetic acid (EDTA) in phosphate buffer saline (PBS). Cells were resuspended in the complete DMEM and the cell numbers were counted by using a hemacytometer. All experiments were performed in triplicate. 


\section{Plant materials and extraction}

Yanang, Tiliacora triandra Diels were purchased from local markets in Pathum Thani, Thailand. Ethanol was used as an extraction solvent due to the semi-polar property of this solvent, which soluble various phytochemical groups more than the use of polar solvents like water or non-polar solvents. Moreover, using ethanolic extract as an active ingredient in pharmaceutical and cosmetic products provided more safety and compatibility than other organic solvent. To extract the plants, they were separately dried at $45^{\circ} \mathrm{C}$ in a hot-air oven. Next, they were ground by using an electric grinder and extracted with various processes of Yanang extraction i.e., maceration technique (MT) and batch stirring extraction (BSE) technique at $30^{\circ} \mathrm{C}$ and $40^{\circ} \mathrm{C}$. The $\mathrm{YL}$ extracts with different extract conditions were then evaporated to dryness under controlled pressure and temperature using a rotary evaporator (Eyela, Tokyo, Japan). The samples of extracts were then compared with total phenolic, antioxidant and stimulating tyrosinase activities.

\section{Determination of DPPH radical scavenging activity assay}

The experimental procedure was modified from the method of Soradech et al. (2016). The YL extracts were diluted with methanol at the concentration of $0.06,0.09,0.12,0.15$, and $0.18 \mathrm{mg} / \mathrm{mL}$. The reaction mixture contained freshly prepared $0.1 \mathrm{mM}$ of DPPH $(100 \mu \mathrm{L})$ and were added with a final volume of $200 \mu \mathrm{L}$ in sterile disposable 96-well microplate for all of the assays. Ascorbic acid served as known antioxidants. Results were determined after $20 \mathrm{~min}$ of reaction time in order to analyze antiradical activities. The disappearance of the free radical DPPH was measured spectrophotometrically at $517 \mathrm{~nm}$ with a microplate reader (Sunrise, Tecan Co., Austria). The percentage inhibition was calculated by the following equation:

$$
\% \text { Inhibition }=((\text { Acontrol }- \text { Asample }) / \text { Acontrol }) \times 100,
$$

where Acontrol was the absorbance of the control reaction (containing all reagents except the test compound), and Asample was the absorbance of test compound. The antioxidant activity was expressed in term of $\mathrm{IC}_{50}$ ( 50 percent of inhibition concentrations). The $\mathrm{IC}_{50}$ values were obtained from linear regression of the percentage (\%) inhibition versus various concentrations of the solution of test substances plot. All measurements were taken in triplicate and the mean values were calculated.

\section{Determination of stimulating tyrosinase enzyme activity}

The stimulating tyrosinase enzyme activity was determined using tyrosinase activity assay as adapted from Soradech et al. (2016). Three YL extracts were diluted with dimethyl sulfoxide (DMSO) at the concentration of 2, 4, 6, 8, and $10 \mathrm{mg} / \mathrm{mL}$. The dilution of extract was mixed with tyrosinase enzyme $(100 \mu \mathrm{g} / \mathrm{mL})$ in phosphate buffer $\mathrm{pH} 6.8$ and then incubated at $37^{\circ} \mathrm{C}$ for $10 \mathrm{~min}$. After that, the samples were added with $2 \mathrm{mM}$ tyrosine $(100 \mu \mathrm{L})$ and incubated at $37^{\circ} \mathrm{C}$ for $40 \mathrm{~min}$. After incubation, the absorbance of solution was determined by using a microplate reader (Sunrise, Tecan Co., Austria) at $450 \mathrm{~nm}$. The percentage of stimulation was calculated by the following equation (1):

$$
\% \text { Inhibition }=((\text { Acontrol }- \text { Asample }) / \text { Acontrol }) \times 100,
$$

where Acontrol was the absorbance of the control reaction (containing all reagents except the test compound) and A sample was the absorbance of test compound. The stimulating activity was expressed in term of $\mathrm{SC}_{50}$ ( 50 percent of stimulation concentrations). The $\mathrm{SC}_{50}$ values were obtained from linear regression of the percentage (\%) stimulation versus various concentrations of the solution of test substances plot. All measurements were taken in triplicate and the mean values were calculated.

\section{Cytotoxicity test of YL extract}

The YL extract was tested for cytotoxicity to human dermal skin fibroblast (HDSF) and melanoma $\left(\mathrm{B}_{16} \mathrm{~F}_{10}\right)$ cells by the SRB assay as previous described (Manosroi et al., 2006). The cells were plated at the density of $1.0 \times 104$ cells/well in 96-well plates and left overnight for cell attachment on the plate in $5 \%$ $\mathrm{CO}_{2}$ at $37^{\circ} \mathrm{C}$. Cells were then exposed to five serial concentrations of the crude extracts and microemulsions $(0.0001-1 \mathrm{mg} / \mathrm{mL})$ for $24 \mathrm{hrs}$. After incubation, the adherent cells were fixed in situ, washed and dyed with SRB. The bound dye was solubilized and the absorbance was measured at $540 \mathrm{~nm}$ by a microplate reader (Sunrise, Tecan Co., Austria). The experiments were done in triplicate. The percentages of cell proliferation were calculated according to the following equation:

$$
\text { Cell ability }(\%)=(\mathrm{A} / \mathrm{B}) \times 100 \text {, }
$$

where A was the absorbance of the sample and B was the absorbance of the control (absolute ethanol).

\section{Determination of melanin content}

The melanin content of YL extract was performed using the method as adapted from Manosroi et al. (2013). Briefly, cells at the density of $10 \times 10^{4}$ cells/well were plated in 6-well plates and incubated overnight for cell adhesion. Various concentrations of the YL extract, theophylline and absolute ethanol were then added and incubated for $72 \mathrm{hrs}$. After removing the medium and washing with PBS, the cells were dissolved in $500 \mu \mathrm{l}$ of $2 \mathrm{~N}$ sodium hydroxide for $1 \mathrm{hr}$ at $60^{\circ} \mathrm{C}$. The absorbance was measured at $450 \mathrm{~nm}$ using a microplate reader (Sunrise, Tecan Co., Austria) and the melanin content was determined in comparing to the standard synthetic melanin. The total protein content of the sample was measured by the Bradford dye-binding method using bovine serum albumin as a standard. For the determination of the actual melanin formation from the same numbers of cells, the melanin content of each treatment was divided by the total protein content. The percentage of the relative ratio of melanin content was calculated as the following formula:

$$
\text { Relative ratio of the melanin content }(\%)=(\mathrm{Mt} / \mathrm{Mc}) \times 100 \text {, }
$$

where Mt was the melanin content of the sample divided by the total protein content of the sample and Mc was the melanin content of the control divided by the total protein content of the control (absolute ethanol).

\section{Pseudoternary phase diagram}

The pseudoternary phase diagram was developed for the microemulsions (ME) consisting oil mixture (jojoba oil, sesame oil, rice bran oil, bergamot, olive oil, coconut oil and oleic acid) as an 
oil phase, tween 80 as a surfactant, $95 \%$ ethanol as a co-surfactant, and deionized water. The pseudoternary phase diagram of oil was constructed using various ratio of tween 80 as a surfactant: $95 \%$ ethanol as a co-surfactant. The ratios of tween 80 to $95 \%$ ethanol were $1: 1,2: 13: 1,4: 1,5: 1,6: 1$ or $7: 1$. The suitable ratio of surfactant and co-surfactant for ME formation was 7:1. Further study was design to develop ME for hair treatment formulation by varying the ratio of oil mixture: PEG 12 dimethicone at 1:1, 1:2 and $2: 1$.

\section{Preparation of ME and YLME}

The composition of the ME was selected from the pseudoternary phase diagram that gave the largest ME area. The selected ME was composed of $6.0-10 \%$ oil mixture, $10.0-15.0 \%$ PEG - 12 dimethicone $40.0-50.0 \%$ tween $80,5.0-10 \%$ ethanol, and $30-50 \%$ water. The microemulsions were prepared by mixing all the components. The YL extract-loaded ME (YLME) was prepared by adding the different concentrations of YL extracts at $0.25,0.5$ and $1 \%(\mathrm{w} / \mathrm{w})$ into an internal phase of ME.

\section{Characterization of ME and YLME}

Physical appearances of ME and YLME were observed in terms of color and transparency. The internal droplet size and polydispersity index (PDI) of all formulations were evaluated using a Zetasizer Nano ZS apparatus (Malvern Instruments Ltd., Worcestershire, UK) at $25^{\circ} \mathrm{C}$. Viscosity of each formulation was determined using a Brookfield (DV II, German) while $\mathrm{pH}$ of microemulsions were determined using $\mathrm{pH}$ meter (Eutech $\mathrm{pH}$ 700, Singapore). Morphology of ME and YLME was investigated by transmission electron microscope (TEM; $80.0 \mathrm{kV}$, TEM 1200 S JEOL, JEOL Ltd., Tokyo, Japan) using a negative staining technique.

\section{Storage conditions}

ME and YLME with different concentrations $(0.25,0.50$ and $1.0 \% \mathrm{w} / \mathrm{w})$ were kept in air-tight containers under accelerated condition using 6 cycles of alternative heating-cooling $\left(4^{\circ} \mathrm{C}\right.$ for 48 $\mathrm{h}$ followed by $45^{\circ} \mathrm{C}$ for $48 \mathrm{~h}$ as 1 cycle).

\section{Physical stability investigation}

Physical appearances including phase separation, transparency, and the sedimentation of ME and YLME were observed. Droplet size, PDI, viscosity and $\mathrm{pH}$ value of the ME and MES were also determined at the end of 6 heating-cooling cycles.

\section{In vitro release}

The in vitro release of YL extract loaded ME was performed using the method as modified from Chansakaow et al. (2017). An aliquot of $1 \mathrm{~mL}$ of $1 \%$ YL extract in aqueous solution and $1 \%$ YL extract loaded in microemulsions in a pre-swollen dialysis bag (CelluSep ${ }^{\circledR}$ Nominal T1, Molecular Weight Cutoff 3,500 Da, Membrane Filtration Products, Inc.) was placed into $100 \mathrm{~mL}$ of Phosphate Buffer $\left(\mathrm{pH} \mathrm{7.4)}\right.$ at $37^{\circ} \mathrm{C}$ for $24 \mathrm{hrs}$ with shaker incubator (ES-20, Korea) at $200 \mathrm{rpm}, 37^{\circ} \mathrm{C}$. A volume of $5 \mathrm{~mL}$ of the receiving medium was withdrawn in differing time periods and the volume was adjusted by the fresh medium. The amount of phenolic content in the various samples was measured using UV visible spectrophotometer at $765 \mathrm{~nm}$, as adapted from Soradech et al. (2017).

\section{Cytotoxicity test of YLME}

The YLME was tested for cytotoxicity to human dermal skin fibroblast (HDSF) and melanoma $\left(\mathrm{B}_{16} \mathrm{~F}_{10}\right)$ cells by the SRB assay as previous described Manosroi et al. (2006). The cells were plated at the density of $1.0 \times 10^{4}$ cells/well in 96 -well plates and left overnight for cell attachment on the plate in $5 \% \mathrm{CO}_{2}$ at $37^{\circ} \mathrm{C}$. Cells were then exposed to five serial concentrations of the crude extracts and microemulsions $(0.0001-1 \mathrm{mg} / \mathrm{mL})$ for $24 \mathrm{hrs}$. After incubation, the adherent cells were fixed in situ, washed and dyed with SRB. The bound dye was solubilized and the absorbance was measured at $540 \mathrm{~nm}$ by a microplate reader (Sunrise, Tecan Co., Austria). The experiments were done in triplicate. The percentages of cell proliferation were calculated according to the following equation:

$$
\text { Cell ability }(\%)=(\mathrm{A} / \mathrm{B}) \times 100 \text {, }
$$

where A was the absorbance of the sample and B was the absorbance of the control (absolute ethanol).

\section{Data analysis}

All experimental measurements were triplicate performed. Result values were expressed as mean value \pm standard deviation. Statistical significance in this study was examined using analysis of variance (ANOVA). The value of $p<0.05$ was considered statistical significant.

\section{RESULTS AND DISCUSSION}

\section{Total phenolic content, antioxidant and stimulating tyrosinase activities}

Total phenolic content, antioxidant and stimulating tyrosinase activities of the YL extracts with different extract conditions were then compared in order to select the most appropriate extract conditions for the YL crude extract as shown in Table 1 and Figure 1. The results demonstrated that the total phenolic contents of three YL extracts were 5015.00 \pm 3.82 , $5802.22 \pm 4.11$ and $5913.06 \pm 4.81 \mathrm{mg} \mathrm{GAE} / 100 \mathrm{~g}$ extract for maceration technique (MT), batch stirring extraction technique (BSE) at $30^{\circ} \mathrm{C}$ and $40^{\circ} \mathrm{C}$, respectively. The increasing total phenolic content of the YL extract was significant $(p<0.05)$ and was obtained using a BSE technique at $30^{\circ} \mathrm{C}$ and $40^{\circ} \mathrm{C}$. The total phenolic content correlated with the antioxidant and stimulating tyrosinase activities. Antioxidant activity was evaluated by DPPH radical scavenging assay which was expressed in terms of the inhibition concentration of radical scavenging at $50 \%\left(\mathrm{IC}_{50}\right)($ Table 1). The YL extracts with different extract conditions exhibited high potential for $\mathrm{DPPH}$ radical scavenging with the $\mathrm{IC}_{50}$ of 0.1007 $\pm 0.01,0.0968 \pm 0.01$ and $0.1131 \pm 0.01 \mathrm{mg} / \mathrm{mL}$, respectively. This result was in accordance with a high total phenolic content of YL extracts due to a correlation between radical scavenging activity and total phenolic content. The antioxidant properties of herbs may be attributed to the main components of each herbal extract which may act as an antioxidant (Soradech et al., 2016; Acharya and Hartley, 2017). The stimulating tyrosinase enzyme activity was evaluated using tyrosinase activity assay as described in terms of stimulating tyrosinase at $50 \%\left(\mathrm{SC}_{50}\right)$. The YL extracts with different extract conditions were found to have stimulating tyrosinase activity with $\mathrm{SC}_{50}$ of $3.74 \pm 0.05,3.46 \pm 0.01$ and 3.97 
$\pm 0.02 \mathrm{mg} / \mathrm{mL}$, respectively (Table 1 and Figure 1 ). The higher stimulating tyrosinase activity was achieved from YL extract with a BSE technique at $30^{\circ} \mathrm{C}$. The higher stimulating tyrosinase activity may be attributed to the high production of melanin content due of the importance of this enzyme in the role of melanin production and such results agree strongly with the results obtained from the research of Somvong and Prasitpuriprecha (2013). They found that the ethyl acetate extract of $T$. triandra had the strongest stimulating tyrosinase activity with a rate of $94.34 \%$ stimulation. Therefore, the higher total phenolic, the higher the DPPH radical scavenging and stimulating tyrosinase activity rates obtained from YL extract with BSE technique at $30^{\circ} \mathrm{C}$ would be. This condition was selected to further study the cytotoxicity, stimulation of melanin content and formulation of microemulsions.

Table 1: Total phenolic content, antioxidant and stimulating tyrosinase activities of YL extracts with different extract conditions.

\begin{tabular}{|c|c|c|c|}
\hline Condition for YL extraction & $\begin{array}{l}\text { Total phenolic content } \\
\text { (mg GAE/100 g extract) }\end{array}$ & $\begin{array}{l}\text { Antioxidant activity using DPPH assay } \\
\qquad\left(\mathrm{IC}_{50}, \mathrm{mg} / \mathrm{mL}\right)\end{array}$ & $\begin{array}{l}\text { Stimulating tyrosinase activity } \\
\qquad\left(\mathrm{SC}_{50}, \mathrm{mg} / \mathrm{mL}\right)\end{array}$ \\
\hline YL extract_MT & $5015.00 \pm 3.82$ & $0.1007 \pm 0.01$ & $3.74 \pm 0.05$ \\
\hline YL extract_BSE_30 $30^{\circ} \mathrm{C}$ & $5802.22 \pm 4.11$ & $0.0968 \pm 0.01$ & $3.46 \pm 0.01$ \\
\hline YL extract_BSE_ $40^{\circ} \mathrm{C}$ & $5913.06 \pm 4.81$ & $0.1131 \pm 0.01$ & $3.97 \pm 0.02$ \\
\hline
\end{tabular}

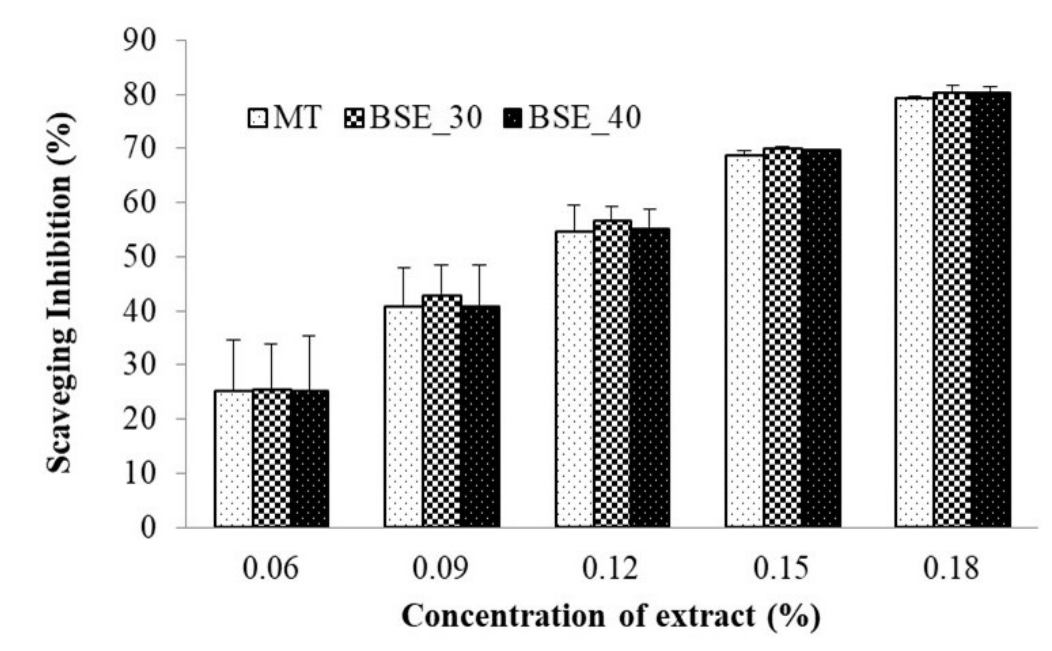

(1a)

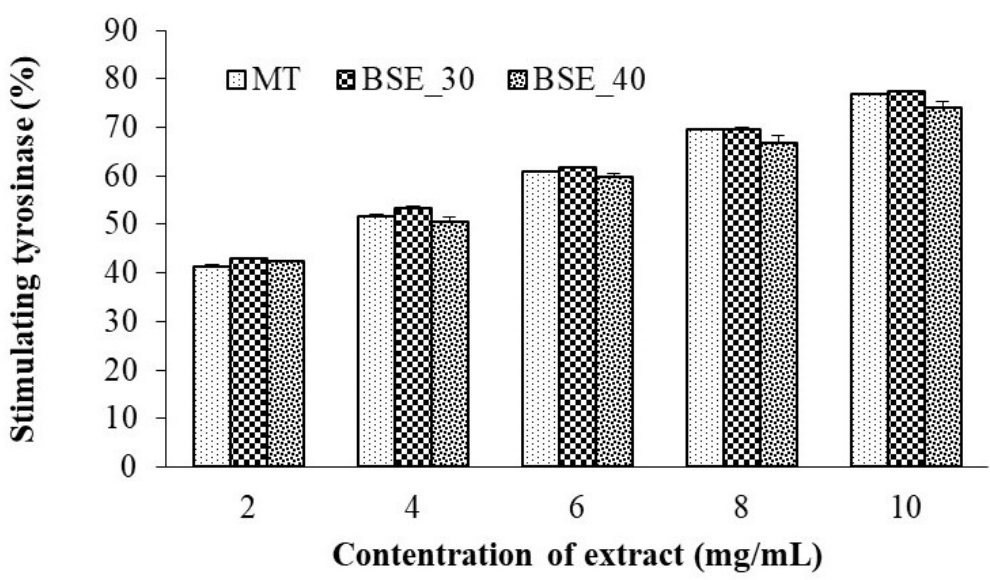

(1b)

Fig. 1: Antioxidant (1a) and stimulating tyrosinase (1b) activities of YL extracts with different extract conditions.

\section{Cytotoxicity test and stimulating the melanin content of YL} extract

The cytotoxicity test results of YL extract to human dermal skin fibroblast (HDSF) and melanoma $\left(\mathrm{B}_{16} \mathrm{~F}_{10}\right)$ cells are displayed in Table 2. These results show that no cytotoxic to HDSF and melanoma $\left(B_{16} F_{10}\right)$ cells at $0.001-1.0 \mathrm{mg} / \mathrm{mL}$ were obtained. The cytotoxicity reading of YL extract corresponded to the stimulating melanin content of YL extract, as shown in Figure 2. The YL extracts at concentrations of $0.05-1.0 \mathrm{mg} / \mathrm{mL}$ showed the potential of stimulating melanin content ranging from 128.69 $131.46 \%$, compared with theophylline as a reference drug. The highest rate of stimulating melanin content of YL extract was obtained at $0.1 \mathrm{mg} / \mathrm{mL}$. 
Table 2: Cytotoxicity test of YL extract on human dermal skin fibroblast (HDSF) and melanoma cells $\left(\mathrm{B}_{16} \mathrm{~F}_{10}\right)$.

\begin{tabular}{ccc}
\hline \multirow{2}{*}{$\begin{array}{c}\text { Concentrations of extract } \\
(\mathbf{m g} / \mathbf{m L})\end{array}$} & \multicolumn{2}{c}{ Cell viability $(\%)$} \\
\cline { 2 - 3 } & HDSF & Melanoma $\left(\mathbf{B}_{16} \mathbf{F}_{10}\right)$ \\
\hline 0.0001 & $97.86 \pm 6.29$ & $101.22 \pm 5.41$ \\
0.001 & $99.42 \pm 4.69$ & $99.28 \pm 3.89$ \\
0.01 & $101.27 \pm 7.34$ & $98.46 \pm 4.91$ \\
0.1 & $103.70 \pm 7.91$ & $97.96 \pm 5.25$ \\
1.0 & $109.77 \pm 4.36$ & $95.76 \pm 5.25$ \\
\hline
\end{tabular}

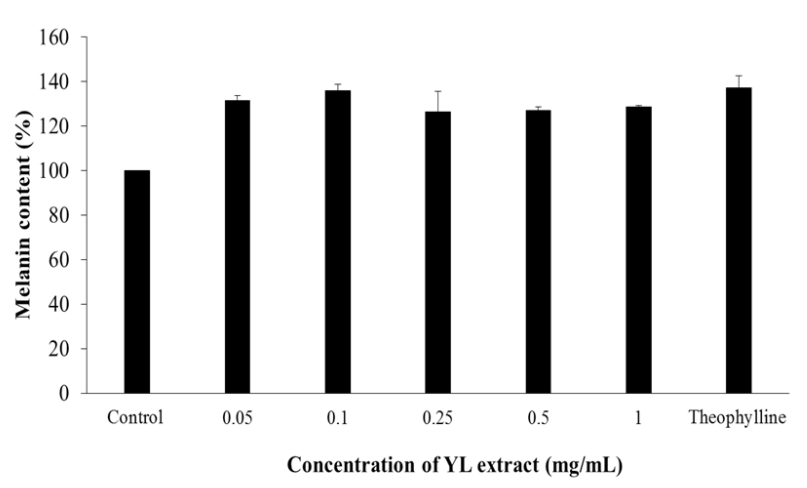

Fig. 2: Stimulating melanin contents of various concentration of YL extract.

\section{Pseudoternary phase diagram of ME}

The pseudoternary phase diagram of the oil mixture (jojoba oil, sesame oil, rice bran oil, bergamot, olive oil, coconut oil and oleic acid) was constructed using various ratios of Tween 80 as a surfactant: ethanol as a co-surfactant. Pseudo-ternary phase diagrams varying the weight ratios of water, oil mixture and Smix (Tween 80 and ethanol) were constructed. The ratios of Smix (Tween 80:ethanol) were 1:1, 2:1 3:1, 4:1, 5:1, 6:1 or $7: 1$. The proper ratio of Smix for ME was $7: 1$ (Figure 2a) due to the clear ME, high stability in terms of size and size distribution after alternative heating and cooling for 6 cycles while a lower ratio exhibited an unstable result, contributing to separation and instability. The co-surfactants penetrated into the interface between the oil and the water phases, resulting in a decrease in the surface tension, an increase in the flexibility of the surfactant film, and an increase in the water solubility (Kawakima et al., 2002; Hussain et al., 1997). Even oils play an important role in MEs because of their effects on the ME area and their drug-loading efficiency (Kogan and Garti, 2006). A further study has been designed to develop MEs for hair treatment formulation by varying the ratio of the oil mixture to PEG 12 dimethicone at ratios of $1: 1,1: 2$ and $2: 1$. The results showed that the appropriate ratio of the oil mixture to PEG-12 dimethicone is 1:2 due to the clearness of the $\mathrm{ME}$ and high stability in terms of sizes and size distribution after alternative heating and cooling for 6 cycles (Figure 2b).

\section{Physicochemical characterization of ME and YLME}

The physicochemical properties i.e., sizes, PDI, $\mathrm{pH}$ and viscosity of ME and YLME are shown in Table 3. The physical appearance of $\mathrm{ME}$ was a yellowish transparent liquid for $\mathrm{ME}$ and a brown transparent liquid for YLME. The droplet sizes were 10.29 $\pm 0.06,11.56 \pm 0.19,12.26 \pm 0.18$, and $11.90 \pm 0.09$ for blank ME, $0.25 \%$ YLME, $0.50 \%$ YLME and $1.0 \%$ YLME, respectively. The polydisperse index (PDI) of ME was significantly increased $(p<0.05)$ from 0.11 to 0.23 when adding the YL extract into the formulation. The concentration of the extract did not influence the size and PDI of ME formulations. The $\mathrm{pH}$ of MEs decreased from 6.26 to 5.94 when the YL extract was increased to $1.0 \%$, while the viscosity of ME increased from 645.23 to $843.50 \mathrm{CPs}$ when the YL extract was added to $1.0 \%$ YLME. The effect of concentrations of YL extracts on the change in all parameters of MEs were due to the phytochemical constituents of YL extract containing phenolic, chlorophyll, alkaloids and flavonoids (Soradech et al., 2017). Figure 4 displays the morphology of ME and 1\% (w/w) YLME. The results indicated the spherical shape of internal droplet sizes of ME with (Figure 4b) and without (Figure 4a) YL extract.

Table 3: Physicochemical characterization of ME and YLME.

\begin{tabular}{ccccc}
\hline Sample & Sizes $(\mathbf{n m})$ & PDI & pH & Viscosity (CPs.) \\
\hline ME & $10.29 \pm 0.06$ & $0.11 \pm 0.01$ & $6.26 \pm 0.01$ & $645.23 \pm 3.06$ \\
$0.25 \%$ YLME & $11.56 \pm 0.19$ & $0.20 \pm 0.03$ & $6.30 \pm 0.01$ & $749.13 \pm 1.53$ \\
$0.50 \%$ YLME & $12.26 \pm 0.18$ & $0.21 \pm 0.01$ & $6.18 \pm 0.00$ & $657.23 \pm 4.16$ \\
$1.0 \%$ YLME & $11.90 \pm 0.09$ & $0.23 \pm 0.01$ & $5.94 \pm 0.01$ & $843.50 \pm 10.84$ \\
\hline
\end{tabular}

\section{Stability studies of ME and YLME}

Figure 5 shows the stability studies of ME and YLME. Results indicated that ME and YLME of all concentrations were physically stable after 6 cycles. The organoleptic properties of ME and YLME showed that there were no change in color and odor after 6 cycles. The homogeneity of the microemulsions was also good. There was also no phase separation in all formulation of microemulsions after 6 cycles. Although there was a tendency of increasing the droplet size and PDI of ME, however, it was still in the range of microemulsions formation. There was also no significant change in $\mathrm{pH}$ and viscosity. The sedimentation and phase separation of ME and YLME did not occur due to the high stable of microemulsions. Therefore, a unique property of ME is their ability to improve the solubility and physical stability of loaded active compounds (Kawakima et al., 2002; Hussain et al., 1997). Due to the high amount of surfactant used in ME, the solubility of the YL extract in the ME was better than that of YL extract in aqueous solution. Physical stability of the YL extract was consequently improved by loading into ME since sedimentation did not occur. Therefore, YL extract solubility and physical stability were successfully improved using the formation of ME.

\section{In vitro release}

The ability of YLME to release phenolic compounds was determined by the In vitro release study as shown in Figure 6. The release rate of YLME was compared with YL extract in aqueous solution. The results indicate that YL extract in the ME was released more slowly than YL extract in aqueous solution. Therefore, the formation of YL extract loaded in ME could contribute to the controlled release of the active antioxidant and melanogenesis stimulating activities from YL extract. 

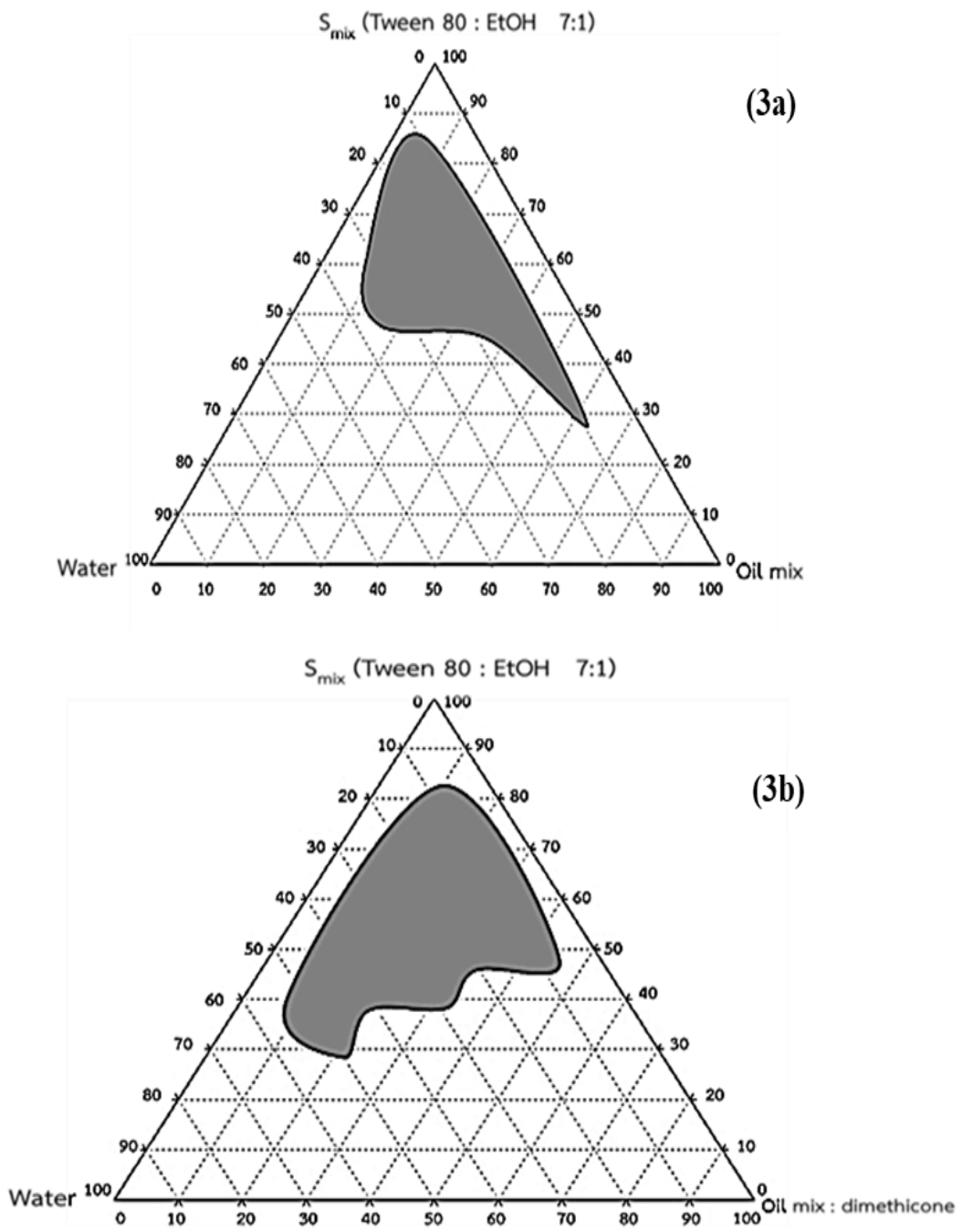

Fig. 3: Psedoternary phase diagram of ME.
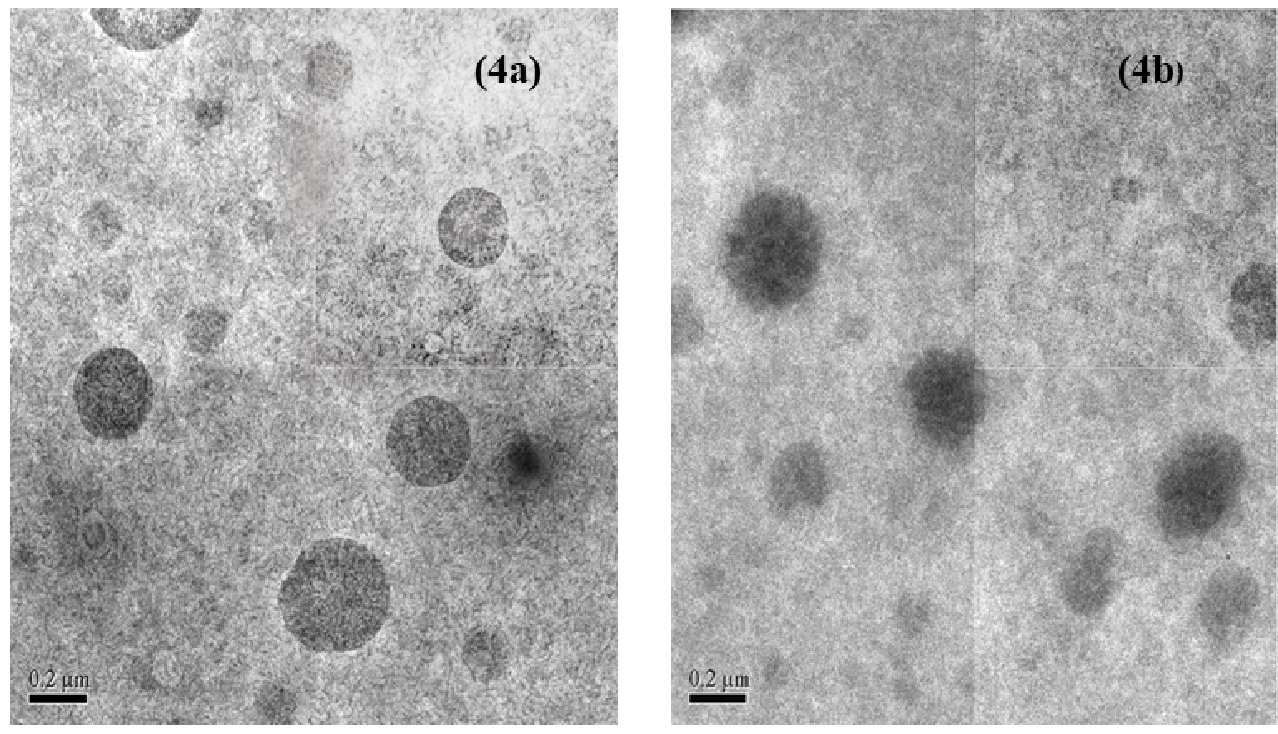

Fig. 4: Transmission electron microscope of ME (4a) and 1\% YLME (4b). 

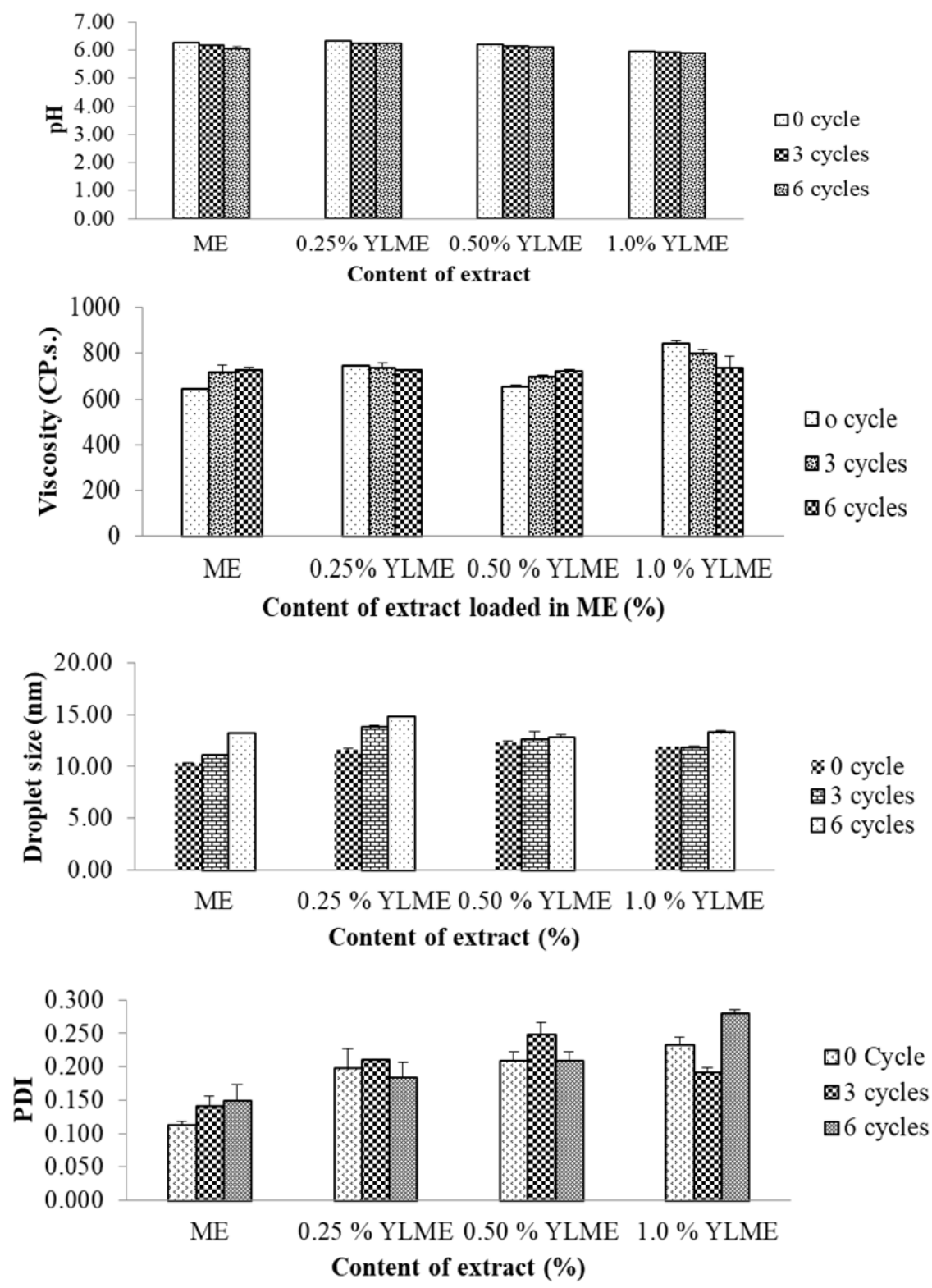

Fig. 5: Stability studies of ME and YLME after alternative heating and cooling for 6 cycles.

\section{Cytotoxicity test of YLME}

As demonstrated in Table 4, the percentage of viability of human dermal skin fibroblast (HDSF) and melanoma cells $\left(\mathrm{B}_{16} \mathrm{~F}_{10}\right)$ varied with the concentrations of YLME ranging from 0.0001 to $1.0 \mathrm{mg} / \mathrm{mL}$. The results showed that they had no cytotoxic to HDSF and melanoma cells at 0.001 to $1.0 \mathrm{mg} / \mathrm{mL}$ with the cell viability ranging from 98.45 to $104.16 \%$ for HDSF cells and $82.15-102.76 \%$ for melanoma cells, respectively. The skin irritation using a single patch test will be further investigated to ensure the safety standards of YLME are met in order to further utilize this active ingredient in hair care cosmetic products.

\section{CONCLUSION}

When the was a higher total phenolic, there would be more DPPH radical scavenging and stimulating tyrosinase activity obtained from YL extract with BSE technique at $30^{\circ} \mathrm{C}$. No cytotoxic to human dermal skin fibroblast and melanoma $\left(\mathrm{B}_{16} \mathrm{~F}_{10}\right)$ cells at $0.001-1.0 \mathrm{mg} / \mathrm{mL}$ and its potential on stimulating melanin content at $0.05-1.0 \mathrm{mg} / \mathrm{mL}$ of YL extracts were both achieved. The YL extract can be prepared in microemulsions as a carrier for a herbal extract delivery system. The thermodynamically stable microemulsions (ME) of the T. triandra Diels (YL) extracts were successfully developed to improve the stability and were able to be control-release more so compared with the extract in aqueous solution. The physical appearances of the YL extracts were maintained after loading into the ME. The release rate of the phenolic content of the YL extract from the ME was slower than that of the aqueous formulation. The YL extract loaded ME showed no cytotoxic to human dermal skin fibroblast and melanoma $\left(B_{16} F_{10}\right)$ cells at 0.001 to $1.0 \mathrm{mg} / \mathrm{mL}$. Therefore, the 
obtained stable microemulsions (ME) of the YL extracts exhibited good characteristics in terms of being a potential active ingredient in antioxidant and melanogenesis stimulating activities. Further investigation will evaluate skin penetration and skin irritation of YLME along with the performance of clinical trials in anti-gray hair products.

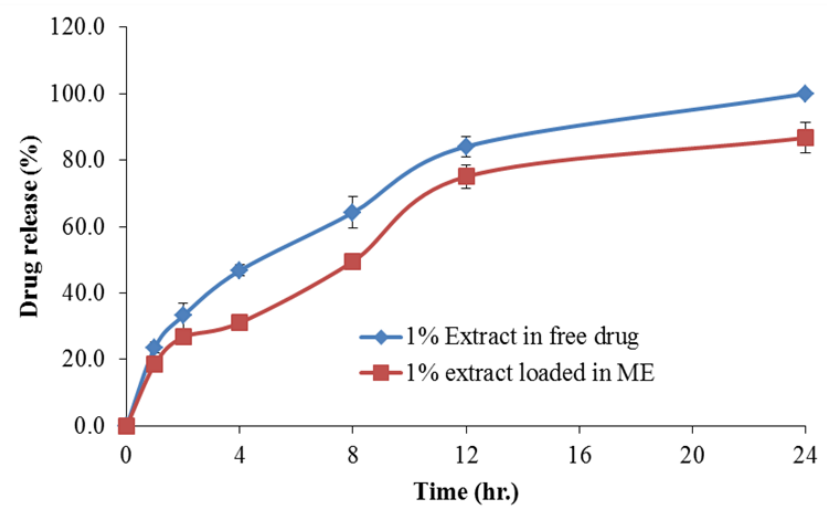

Fig. 6: Active release of 1\% YL extract in aqueous solution and 1\% YLME.

Table 4: Cytotoxicity test of 1\% YLME on human dermal skin fibroblast (HDSF) and melanoma cells $\left(\mathrm{B}_{16} \mathrm{~F}_{10}\right)$.

\begin{tabular}{ccc}
\hline \multirow{2}{*}{$\begin{array}{c}\text { Content of microemulsions } \\
(\mathbf{m g} / \mathbf{m L})\end{array}$} & \multicolumn{2}{c}{ Cell viability $(\%)$} \\
\cline { 2 - 3 } & HDSF & Melanoma cell $\left(\mathbf{B}_{\mathbf{1 6}} \mathbf{F}_{10}\right)$ \\
\hline 0.0001 & $104.16 \pm 4.75$ & $102.76 \pm 6.41$ \\
0.001 & $108.43 \pm 3.61$ & $100.26 \pm 2.79$ \\
0.01 & $111.19 \pm 3.75$ & $85.57 \pm 7.50$ \\
0.1 & $126.48 \pm 1.98$ & $82.15 \pm 2.50$ \\
1.0 & $98.45 \pm 3.49$ & $83.37 \pm 3.43$ \\
\hline
\end{tabular}

\section{ACKNOWLEDGMENTS}

This work was supported by the Thailand Institute of Scientific and Technological Research, Ministry of Science and Technology, Thailand.

\section{CONFLICTS OF INTERESTS}

The authors declare that there is no conflict of interest.

\section{REFERRENCES}

Acharya DP, Hartley PG. Progress in microemulsion characterization. Curr Opin Colloid Interface Sci. 2012; 17: 274-280.

Chansakaow S, Sirisa-ard P, Prepartion R. Characterization and anti-oxidation activity of xanthone-loaded making (Hodgsonia Heteroclite) microemulsions. Int J Pharm Pharm Sci 2017; 9(3):262-267.

Hussain A, Luckham PF, Tadros TF. Phase behavior of $\mathrm{pH}$ dependent microemulsions at high temperature and high salinities. Imperial College Sci 1997; 52:228-231.

Kawakima K, Yoshikawa T, Moroto Y. Microemulsion formulation for enhanced absorption of poorly soluble drugs. J Control Release 2002; 81:65-74.

Kogan A, Garti N. Microemulsions as transdermal drug delivery vehicles. Adv Colloid Interface Sci. 2006; 123-126:369-385.

Kreilgaard M. Influence of microemulsion on cutaneous drug delivery. Adv Drug Deliv Rev 2002; 1 (54):77-98.

Manosroi A, Chaikul P, Manosroi W, Manosroi J. Melanogenesis of methyl myristate loaded niosomes in $\mathrm{B}_{16} \mathrm{~F}_{10}$ melanoma cells. J. Biomed Nanotechnol. 2013; 9(4):626-38.

Manosroi J, Dhumtanom P, Manosroi A. Anti-proliferative activity of essential oil extracted from Thai medicinal plants on $\mathrm{KB}$ and P388 cell lines. Cancer Lett 2006; 235:114-120.

Somvong K, Prasitpuriprecha C. Antioxidant and Melanogenesis Stimulating activities of Some Thai Traditional Medicinal Plant Extracts for Grey Hair Treatment. The 4th Annual Northeast Pharmacy Research Conference of 2012 "Pharmacy Profession in Harmony" Faculty of Pharmaceutical Sciences, Khon Kaen University, Thailand.

Soradech S, Kajsongkram T, Rotamporn S, Panapong K, Kusolkumbot P, Kuson S, Thumthimthed, S. Phytochemical Constituent and Antioxidant Activity of Yanang (Tiliacora triandra) Leave Ethanolic Extract. TJPS 2017; 41 (Suppl):165-168.

Soradech S, Kusolkumbot P, Reungpatthanaphong P, Thubthimthed S. "Investigation of DPPH Radical Scavenging, Antioxidant and Melanogenesis Stimulating Activities of Various Pigment Extracts from Thai Herbal Plants. RJPBCS 2016; 7 (4):393-399.

Soradech S, Reungpatthanaphong P, Tangsatirapakdee S, Panaphong K, Thammachat T, Manchun S, Thubthimthed S. Radical scavenging, antioxidant and melanogenesis stimulating activities of different species of rice (Oryza sativa L.) extracts for hair treatment formulation. TJPS 2016; 40 (Suppl):92-95.

Teansuwan N, Sripanidkulchai B, Jaipakdee N. Effect of four herb extracts on melanin synthesis. IJPS 2016; 11 (Suppl):33-42.

Tobin DJ, Paus R. Graying: gerontobiology of the hair follicle pigmentary unit. Exp Gerontol 2001; 36 (1):29-54.

How to cite this article:

Soradech S, Kusolkumbot P, Thubthimthed S. Development and characterization of microemulsions containing Tiliacora triandra Diels as an active ingredient for antioxidant and melanogenesis stimulating activities. J App Pharm Sci, 2018; 8(03): 046-054. 